Bangladesh J. Bot. 47(4): 887-892, 2018 (December)

\title{
CULTIVATION OF OYSTER MUSHROOM (PLEUROTUS OSTREATUS (JACQ.) P. KUMM.) USING COFFEE WASTE AND PULP TO MITIGATE CAFFEINE AND PULP RELATED POLLUTION
}

\author{
Juan Carlos Calderon Lopez ${ }^{1}$ and Kampanad Bhaktikul \\ Faculty of Environment and Resource Studies, Mahidol University, \\ Nakhon Pathom, 73170, Thailand
}

Keywords: Coffee waste, Coffee pulp, Fortification, Oyster mushroom, Pollution reduction

\begin{abstract}
This paper aims to assess the technical, economic, and financial viability of cultivation of mushroom from coffee waste and pulp. The raw material characteristics and technical aspects were analyzed. In techno economic analysis, the investment is defined, and the financing of the project were explained. It is believed that production of mushroom from coffee waste and pulp is feasible as well as profitable in San Salvador. Use of coffee waste in the production of mushroom will prevent its damping in landfills and thus be friendly to environment as well.
\end{abstract}

\section{Introduction}

In El Salvador, there is little information about the nutritional and medicinal benefits of consuming mushrooms. Although there is a history that the ancestors were experienced on the properties of mushrooms, these were collected at specific times for each species of the rainforest. However, due to the deforestation and indiscriminate felling of forests, the wild production of these species is mainly produced in the forests with coffee and is usually associated with the shadow of the guachipilín tree when it reaches its final phase (Ali 2018). Between the mushrooms stands the tree of Tenquique - Pseudofistulina brasiliensis - which is an edible mushroom of western El Salvador. The cultivation of edible mushroom in El Salvador was unknown, but at the end of the 1980s, an important project of mushroom production of the Pleurotus genus began, adequate quantities of the product were produced but operations were closed for unknown reasons (Baker et al. 2011, Harsh and Joshi 2008). Between 1990 and 1996, The National Agricultural and Forestry Technology Center (CENTA) established a research and culture project for Pleurotus ostreatus for finding alternative solutions to food problems, determining the minimum requirements to establish fungal crops in the country and contributing to agricultural diversification (Chang 2006). Coffee production is an industry in which more pollutants are emitted into the environment for only $0.2 \%$ of the production. According to studies, some landfills are treated and others are not, causing heavy pollution due to methane fermentation which produces 20 times more greenhouse $\mathrm{CO}_{2}$ (Khan et al. 2018).

Therefore, keeping in view of such facts, the present study analysed the feasibility of the reuse of by-products in the agribusiness of coffee for cultivating the oyster mushroom, which has the ability to use any type of substrate and which is highly adaptable to the climate and coffee pulp produced by industries and households (Croushore 2006, Naidu et al. 2018). In addition, once the mushrooms have been cultivated, what used to be coffee now becomes excellent compost for nourishing soils and orchards. This production technology in this substrate not only prevents gas

*Author for correspondence: <juancarlos.cal@mahidol.ac.th>. ${ }^{1}$ Faculty of Agricultura e Investigación Agrícola, Dr. José Matías Delgado University, El Salvador, Central America. 
emissions from occurring, but returns to the land for its nutrients (Creswell 2005, Farr 1983). The use of coffee pulp and coffee waste (coffee by-products) is a good and new alternative in the business. Additionally, it helps the environment and the Salvadoran economy by decreasing imports and providing more jobs and economic and ecological sustainability as it becomes a closed cycle of production without contaminants. These projects are direly needed in developing countries to provide agricultural production alternatives, which have short production time and do not use large territorial extensions to produce (Wood and Fermor1998). Oyster mushroom production is therefore the alternative for the following two main reasons: (i) The adaptability of this species to different climates and especially to the climate in El Salvador and (ii) as an alternative of green crops that help the environment and do not contaminate it by using byproducts derived from different types of agro-industry and in this case, the coffee agro-industry. The main objective of the study is to prepare the technical and financial feasibility of oyster mushroom culture from coffee and pulp waste.

\section{Materials and Methods}

The study area was in the subdivision of Rosario in the municipality of San Martín, San Salvador and it is located in the western area of San Salvador and bordered on the north by San José Guayabal. As previously described, the study examined two main components of the project, i.e., its technical and its financial feasibility. The engineering of mushroom cultivation from coffee waste and pulp involved the construction of two greenhouses. The size of the project was based on the construction of two greenhouse galleys with the required specifications and costs, designed to produce $25 \mathrm{lbs}$ of mushrooms per day starting with the first phase. The same dimensions were used for both greenhouses: $3.5 \mathrm{~m}$ wide and $5 \mathrm{~m}$ long. If well maintained, the greenhouses have a six-year lifespan (Ali et al. 2018). Total construction and installment costs for the project were almost El Salvadorian dollar (\$) 962.00. A warm climate provides ideal weather conditions, and for this reason, San Salvador was chosen. The vegetation comprises humid subtropical forest. The working capital was quantified according to the lag-period method on the operating costs.

Different costs calculations: $\quad$ TC $=$ FC + VC

NPV and IRR were taken from (Baker et al. (2011), Boateng (2015). Total variable cost (TVC) and breakeven point (BEP) were used. The total variable cost was divided by the number of units produced, remainder will be the unit variable cost, as follows:

$$
\mathrm{NPV}=\sum_{n=0}^{N} \frac{C_{n}}{(1+r)^{n}}=0
$$

where, $C_{n}=$ Net Cash Flow successively every year. $N=$ Years of the Project; the number of cash flows (for example, for this project, the period is seven years; therefore, for considering annual cash flows, this number would be 7). $\mathrm{r}=$ The discount rate (for example, $7 \%$ ). $\mathrm{O}=$ Investment activities minus Working Capital plus Financial Activities (or Net Expenses).

$$
I R R=\sum_{t-1}^{t} \frac{C_{t}}{(1+r)^{t}}-C_{o}
$$

Where:

$C_{t}=$ Net Cash Inflow During the Period $t$

$r=$ Discount Rate

$t=$ Number of Time Periods

$C_{o}=$ Total Initial Investment Cost 


\section{Results and Discussion}

This section explains the initial results obtained from the technical and financial assessment of the implications of the pilot project. Different processes involved in the engineering of the project, such as the technical procedures used for production, the characteristics of the raw materials, the equipment to be used, the justification of the selected size, the labor to be employed and capacity levels required, the distribution of the plant, and the specifications of the civil works were defined; this allows the identification and prevention of possible obstacles to the execution of the project. The project seeks to carry out the cultivation of oyster mushrooms in coffee pulp and ground coffee waste as an alternative means of food production that will mitigate the pollution generated by these by-products. Oyster mushrooms do not need a particular type of soil to grow; they merely require small spaces under cover or in greenhouses. It is important that the cultivation facility is ventilated, dry, and clean. There must be at least four separate areas. The preparation area can be outdoors or in any large space, which facilitates the assembly of the substrate. The sterilization and inoculation area, where the spores of the fungus are sown in the sterilized substrate which must remain aseptic. The incubation area, where the fungus grows while feeding on the chosen substrate, must be clean, completely dark, and maintained at $25^{\circ} \mathrm{C}$ (although the mycelium can also develop at a lower temperature, it will grow more slowly). The fruiting area must be more spacious and admit sufficient light to achieve a state of semi-darkness. A flat space of adequate size to house all of these elements must be built.

For the cultivation of oyster mushrooms, the following raw materials were used: spores or mycelia, substrate (coffee pulp and ground coffee waste), 25-pound bags, quicklime (calcium oxide), and water. For the processing and packaging of the mushrooms that were grown, the following raw materials were used: mushrooms, polyethylene bags, plastic trays, and labels. To facilitate increasingly frequent harvests, the substrate must be available all year round. It is possible to obtain ground coffee waste at any time, but coffee pulp, which provides proteins required for the production of mushrooms, is not always available. Therefore, it is necessary to continue researching alternative substrates containing these proteins since fungi can grow in different substrates. One potentially favorable alternative is coconut straw.

There are eight stages in the mushroom production process: (1) weighing of the coffee pulp, (2) repose of the compost for three to five days, (3) sterilization, (4) distribution (sowing) of the spores, (5) application of the compost, (6) transport of the bags to the incubation area, (7) control of the temperature and humidity and (8) transport of the bags to the production hall for the fruiting stage. Fig. 1 shows some of the laboratory tests and machines used for processing.

Flowchart process:

- In the present pilot project, the first step was to obtain a pure crop of $P$. ostreatus, which was used to provide spores for inoculation.

- Parallel to this, composting of the coffee remnants intended for use as the substrate was performed for 24 hrs.

- Pasteurization lasting between six and eight hrs was carried out.

- The substrate was cooled and then inoculated in an aseptic, dark environment at a temperature of 20 to $26^{\circ} \mathrm{C}$ to induce colonization by the mycelium. Once $100 \%$ colonization was reached, the substrate was moved to a room with a relative humidity of $90 \%$ and a temperature between 20 and $24^{\circ} \mathrm{C}$ in order for the mycelium to fructify.

In implementing this project in El Salvador's municipalities of Santa Tecla and Antiguo Cuscatlán, it was the first to venture into this market segment of mushroom production from coffee waste substrates because there is very little knowledge of this technique. It breaks agricultural paradigms rooted in the culture of Salvadoran coffee producers, and at the same time, 
it mitigates and compensates for the environmental impact of coffee growing by reusing the byproducts of El Salvador's annual coffee production. According to the results, this project is feasible: sufficient supplies, raw materials, infrastructure, land, and human resources will be available to carry out the cultivation of oyster mushrooms at the agro-industrial level. With the start-up of this agro-industrial factory, the national economy will be improved. Moreover, the results obtained from the financial evaluation show that this project will be economically profitable, even if considerable investment is required at the beginning, and it will be possible to

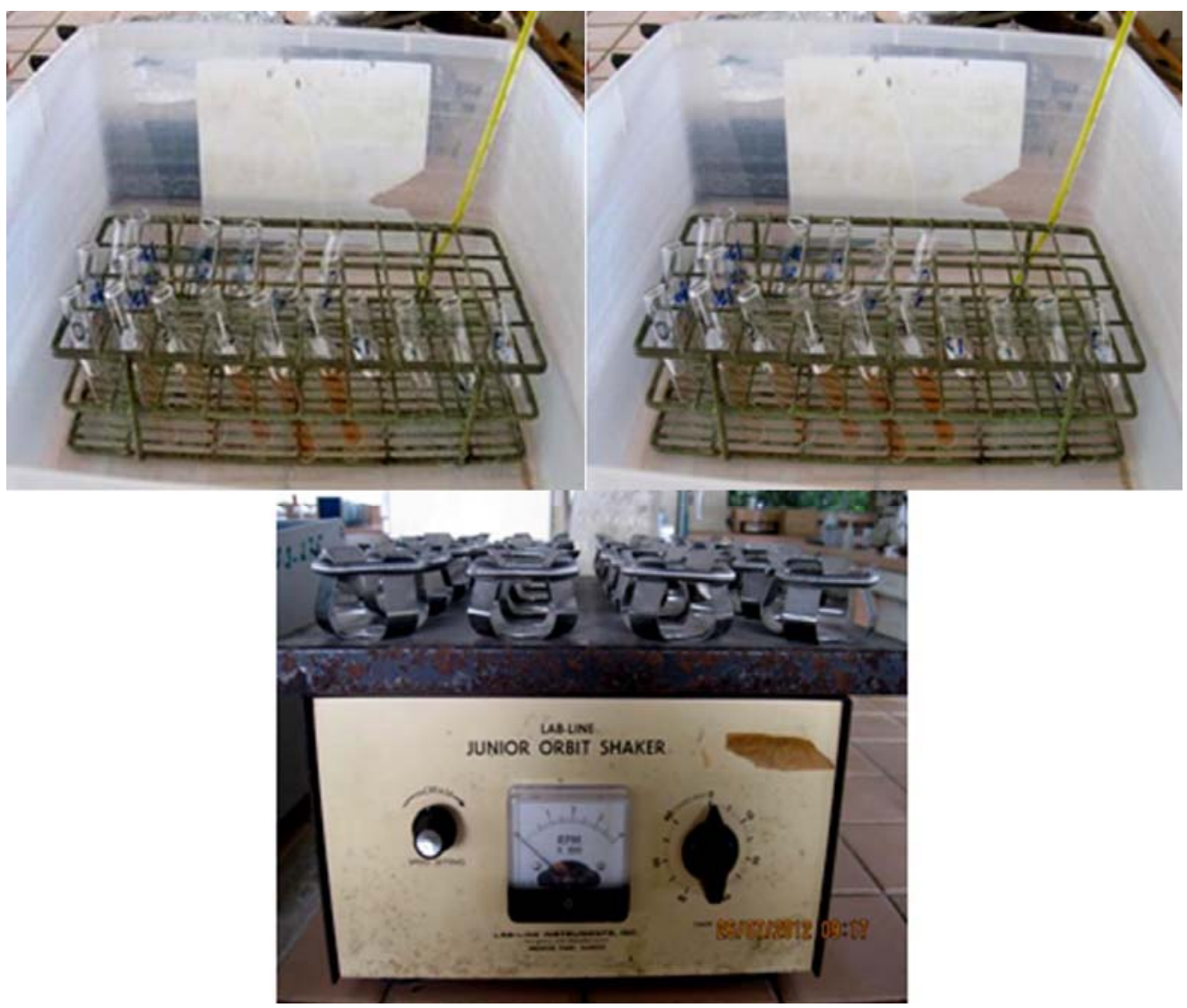

Fig. 1. Equipment used for the physical-chemical analysis of coffee pulp.

increase the capital as the initial investment is recouped. The greenhouses will have a wellmaintained six-year lifespan. The total construction and installment cost for this will be almost \$ 962, based on the Annual Sales Budget chart, which projects an increase in future sales of 3\% every year. Considering that the credit time of the loan from the bank is planned for seven years, the minimum duration of this project will therefore be seven years. Therefore, the project is acceptable (Table 1). Given the predicted internal rate of return (IRR) of $51.47 \%$ per annum, it may be concluded that the money invested will be recovered at a rate of, on average, $51.47 \%$ each year. Finally, for every dollar invested. Approximately \$ 0.52 will be returned (Table 2). 


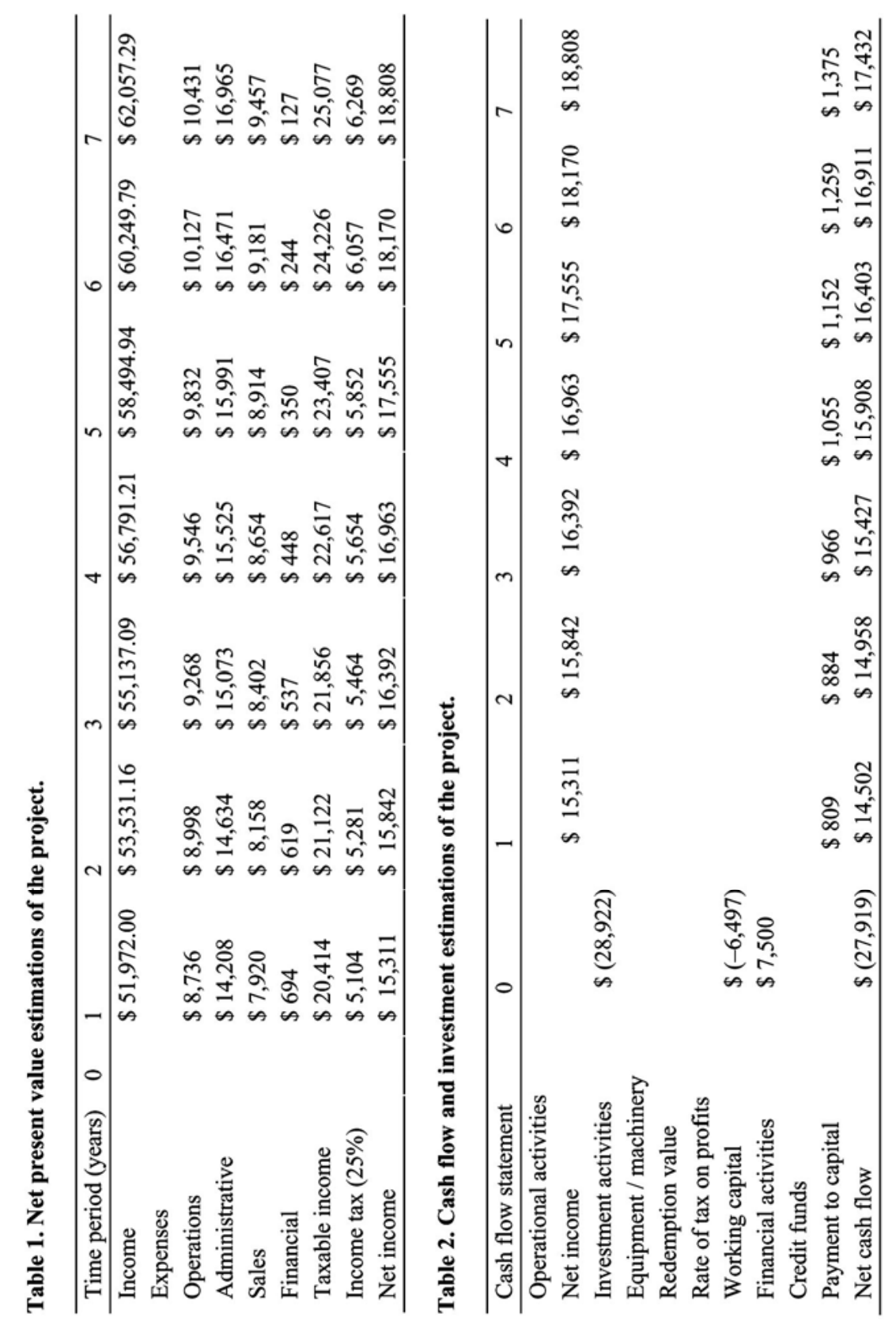


It was found that fundamentally, such production of mushroom from coffee waste and pulp is possible. It is not only financially feasible but environment-friendly as well. Depending on the demand and supply of the local and regional markets, such production is a good alternative to the food and can help in the mitigation of pollution through waste recycling. During the study, it was observed that the demand for this type of food is acceptable, since in the national market, there is very little supply of this product, and it is only available in specialized stores and some supermarkets. In El Salvador, the municipalities of Santa Tecla and Antiguo Cuscatlan, which are implementing this project, will be the first to venture into this market segment through production (substrate), given the general lack of knowledge about this technique. Financial and economic analysis showed that such business will be cost-effective and profitable in the long run. This would also help in cutting down the imports of mushroom in San Salvador and can assist in GDP growth of the country if large-scale projects are started. Last but not the least, such production will also reduce the burden on landfills and the resulting environmental pollution, since waste recycling is involved in this process. Therefore, local and national governments of San Salvador should support such projects through soft financing.

\section{References}

Ali G 2018. Climate change and spatial heterogeneity of Pakistan: Empirical evidence using multidisciplinary approach. Science of the Total Environment 634: 95-108.

Ali G, Pumijumnong N and Cui S 2018. Valuation and validation of carbon sources and sinks through land cover/use change analysis: The case study of bangkok metropolitan area. Land Use Policy 70: 471-478.

Baker M, Wurgler J and Yuan Y 2011. Global, local, and contagious investor sentiment. J. Financial Economics 104: 272-287.

Boateng A 2015. The impact of planning on successful project implementation: a case of GCB bank data scrub project. Unpublished Thesis of University of Cape Coast.

Chang ST 2006. The world mushroom industry: Trends and technological development. Int. J. Med. Mush. 8: 297-314.

Creswell JW 2005. Educational research: Planning, conducting, and evaluating quantitative and qualitative research (2nd ed.). Upper Saddle River, NJ: Pearson Prentice Hall.

Croushore D 2006. Money and Banking: A Policy oriented approach. Cengage Learning.

Farr DF 1983. Mushroom Industry: Diversification with additional species in the United States. Mycologia 75: 351-360.

Harsh NSK and Joshi K 2008. Mushrooms: The vegetable of the future. India, Science and Technology: S \& $T$ for Rural India and Inclusive growth.

Khan MA, Iqbal Z, Hussain M and Rahman IU 2018. Allelopathic effect of leaves on germination of wheat (Triticum aestivum L.). Bangladesh J. Bot. 47(1): 151-154.

Naidoo Y, Sdashiva CT and Naidoo G 2018. Chemical composition and antibacterial properties of the essential oil of Ceratotheca triloba (Bernh.) Hook. F. Bangladesh J. Bot. 47(1): 155-160.

Wood DA and Fermor TR 1988. Nutrition of Agaricus bisporus. In: The biology and technology of the cutivated mushroom. (P.B. Flegg, D.M. Spencer and D.A. Woods, eds). John Wiley and Sons, New York. pp. 43-61. 